\title{
Method for Restoring and Reinforcing Deteriorated Steel Railway Bridges -Development of Integral Bridges with Nail-Reinforced Soil-
}

\author{
Masayuki KODA, Dr. Eng. \\ Laboratory Head, \\ Foundation \& Geotechnical Engineering Laboratory, Structure Technology Division
}

Tomoaki YOKOYAMA

JR Central Consultants Company

Takahiro NONAKA

Assistant Senior Researcher,

Foundation \& Geotechnical Engineering Laboratory, Structure Technology Division

Yusuke KOBAYASHI, Dr. Eng.

Assistant Senior Researcher,

Steel \& Composite Structures Laboratory, Structure Technology Division

\author{
Masaru TATEYAMA, Dr. Eng. \\ Director, \\ Structure Technology Division
}

\begin{abstract}
Japan's railways began operations about 140 years ago. The majority of its steel railway bridges now have 50 years or more of service.

It is therefore expected that the number of steel bridges requiring repair, reinforcement or replacement will increase in the future. Consequently, the Railway Technical Research Institute is proposing a method to extend the life and strengthen the earthquake resistance of deteriorated steel-girder and abutment-type bridges without replacing steel girders, by integrating the following structures:

(1) Abutments and backfills with reinforced concrete (RC) walls that are connected to each other rigidly with nail-reinforced soil;

(2) Connecting steel girders and abutments with reinforced concrete;

These are measures which improve the function of steel girders, abutments and backfills in normal service periods and during earthquakes. Bridges reinforced with this type of structure are called "Integral Bridges with Nail-Reinforced Soil (NRS-Integral Bridges)."
\end{abstract}

Keywords: railway structure, steel bridge, abutment, backfill, maintenance, renewal, aseismic improvement, without replacement

\section{Introduction}

Conventional railways began to be built across Japan since the Meiji Era, creating a vast stock of social capital over the years, including earth structures such as slopes and embankments and bridges, viaducts and tunnels. These structures were built in different eras, which means that their design and the principles according to which they were built, have evolved and some are likely to have deteriorated over time. If a railway structure sustains damage somewhere, the entire railway line is often unable to function. To improve sustainability of the entire railway line therefore, it is recommended that the weaker structures are picked out from among all the structures to be repaired, and reinforced or replaced in order to maintain railway operations and thereby upgrading the entire railway line [1].

Earth structures such as cut slopes and embankments are particularly common railway structures. Renovat- ing all structures of this kind therefore will require time and expense. Nonetheless, in order to achieve the goal of improving the performance and safety of railway lines, it is important to work on weaker structures and gradually move on renovating all structures along a line. The boundary area between the steel girder, the abutment and the backfill, which consists of different kinds of structures, is a weak point in railway lines, since settlement of the backfill can occur under the influence of normal railway operation, or abutments and bearings supporting girders can suffer earthquake damage.

This paper therefore focuses on improving the interfaces between steel girders, abutments and backfills. In order to extend the life and to strengthen the earthquake resistance of deteriorated steel-girder and abutment-type bridges without replacing steel girders, the Railway Technical Research Institute proposed a method where deteriorated steel bridges are integrated with nail-reinforced soil. 
2. Problems affecting deteriorated steel bridges comprising steel-girders, abutments and backfills

Japan's railways began operations about 140 years ago. The majority of its steel railway bridges now have 50 years or more of service.

It is therefore expected that the number of steel bridges requiring repair, reinforcement or replacement will increase in the future. Replacing deteriorated bridges with new ones is both extremely time-consuming and expensive,

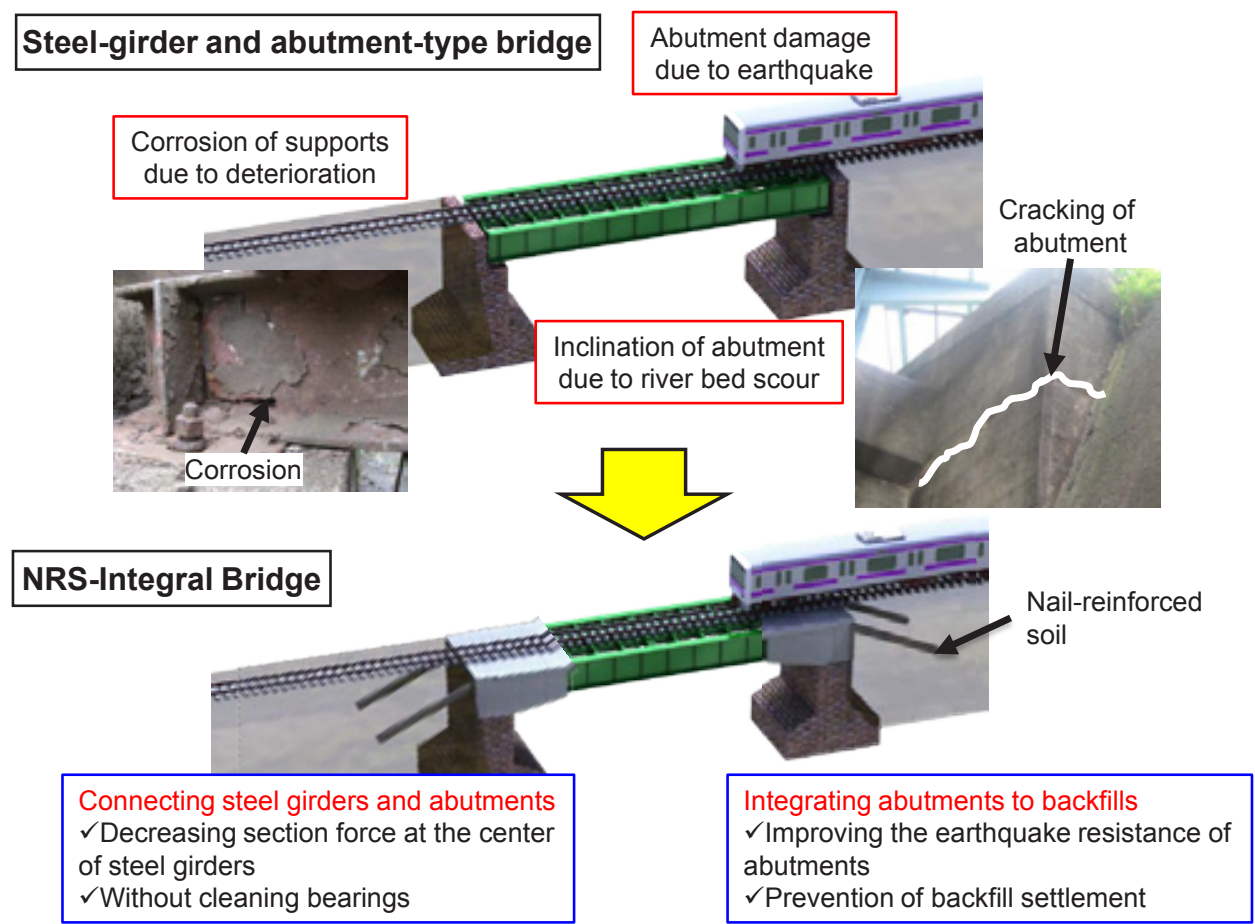

Fig. 1 An outline of NRS-Integral Bridge

Table 1 Problems for the steel-girder and abutment-type bridges and features of the Integral Bridge with Nail-Reinforced Soil(NRS-Integral Bridge)

\begin{tabular}{|c|c|c|c|}
\hline & Object point & $\begin{array}{l}\text { Steel-beam and abutment-type bridge } \\
\text { problems }\end{array}$ & Features of Integral Bridge with Nail-Reinforced Soil \\
\hline $\begin{array}{l}\text { Under } \\
\text { construction / } \\
\text { reinforcement }\end{array}$ & & $\begin{array}{l}\text { - As backfills and beams are constructed and } \\
\text { laid after abutments have been constructed, } \\
\text { abutments are subject to settlement or lateral } \\
\text { displacements. }\end{array}$ & $\begin{array}{l}\text { - Bridge integration work can easily be performed without } \\
\text { manufacture of a new bridge or construction of temporary tracks, } \\
\text { beams, abutments or track rerouting, unlike the method to replace } \\
\text { beams and abutments after constructing temporary tracks. } \\
\text { - Bridge integration work can easily be performed to improve } \\
\text { abutment functions without constructing temporary pedestals when } \\
\text { compared with the method to laterally replace steel beams. }\end{array}$ \\
\hline \multirow[b]{2}{*}{$\begin{array}{l}\text { In the normal } \\
\text { state }\end{array}$} & $\begin{array}{l}\text { Steel beam } \\
\text { - abutment }\end{array}$ & $\begin{array}{l}\text { - Upkeep and control are required for supports. } \\
\text { - Corrosion due to rain water starts from the } \\
\text { supports. }\end{array}$ & $\begin{array}{l}\text { - Elimination of support maintenance and checks } \\
\text { - Decreases in the section force of steel beams generated under } \\
\text { train loads extend the fatigue life of the bridge. }\end{array}$ \\
\hline & $\begin{array}{l}\text { Backfill - } \\
\text { abutment }\end{array}$ & $\begin{array}{l}\text { - Backfills sink, abutments incline or supports } \\
\text { failure. } \\
\text { - Relative displacement may occur between } \\
\text { the backfill and the crown of the abutment, } \\
\text { compromising train operation. Backfills } \\
\text { therefore require control and maintenance. }\end{array}$ & $\begin{array}{l}\text { - Nail-reinforced soil strengthens backfill self-supporting properties, } \\
\text { suppressing settlement. } \\
\text { - Relative displacements between the backfill and abutments are } \\
\text { prevented, reducing the number of man-hours required for } \\
\text { maintenance and checking of backfills. }\end{array}$ \\
\hline \multirow{3}{*}{$\begin{array}{l}\text { In abnormal } \\
\text { states } \\
\text { (Earthquakes, } \\
\text { abnormal } \\
\text { floods) }\end{array}$} & $\begin{array}{l}\text { Steel beam } \\
\text { - abutment }\end{array}$ & $\begin{array}{l}\text { - Supports and abutments may be damaged } \\
\text { during earthquakes. } \\
\text { - Large relative displacements between } \\
\text { backfills and abutments potentially cause } \\
\text { bridges to fall. }\end{array}$ & $\begin{array}{l}\text { - The rigid-frame structure of steel beams and abutments improves } \\
\text { the earthquake resisting performance of the whole bridge. } \\
\text { - Prevention of accidents caused by bridge collapse during } \\
\text { earthquakes }\end{array}$ \\
\hline & $\begin{array}{l}\text { Backfill - } \\
\text { abutment }\end{array}$ & $\begin{array}{l}\text { - Earthquakes may cause abutments to incline } \\
\text { or backfills to sink. } \\
\text { - Large relative displacement between the } \\
\text { backfills and abutments may compromise } \\
\text { safety of train operation during and after } \\
\text { earthquakes. }\end{array}$ & $\begin{array}{l}\text { - NRS-Integral Bridge improves earthquake resistance performance } \\
\text { of abutments and backfills. } \\
\text { - Relative displacement during earthquakes is negligible, ensuring } \\
\text { the safety of train operations. }\end{array}$ \\
\hline & Foundation & $\begin{array}{l}\text { - River bed degradation or abutment scour may } \\
\text { occur with river bridges to potentially cause } \\
\text { abutments to incline. }\end{array}$ & $\begin{array}{l}\text { - River bed degradation and scour do not directly cause decrease in } \\
\text { the supporting force, inclination of abutments or accidents involving } \\
\text { bridge collapse. }\end{array}$ \\
\hline
\end{tabular}


since this requires the building of temporary tracks, erection beams and abutments.

In case of conventional steel-girder and abutment-type bridges, backfills are vulnerable to subsidence due to their own weight, causing sinking and lateral displacement of abutments. Once bridges enter use, various problems can occur, for example:

(1)Phenomena requiring maintenance, such as corrosion of bearings and steel girder flanges below bridge sleepers, and settlement of backfills;

(2)Earthquake damage such as inclination of abutments, backfill settlement and bearings damage.

In 1995 Hyogoken-Nambu Earthquake caused a number of gaps due to settlement between the backfill and the abutment which were larger than the spaces forming in embankment sections [2]. River bridges also have the following disadvantages:

(1)Decrease in horizontal resistance at the front of the abutment due to river bed scouring;

(2)Abutment inclination or sliding due to large relative displacement against steel girders, which potentially leads to collapse of the bridge.

The above-mentioned problems affecting deteriorated steel bridges are shown in Fig. 1 and Table1.

\section{Reinforcement method of Integral Deteriorated Steel Bridges with Nail-Reinforced Soil}

To extend the life and strengthen the earthquake resistance of deteriorated steel-girder and abutment-type bridges without replacing steel girders, the Railway Technical Research Institute proposed a reinforcement method which integrates the deteriorated steel bridges with nailreinforced soil. Details of the structure are as follows:
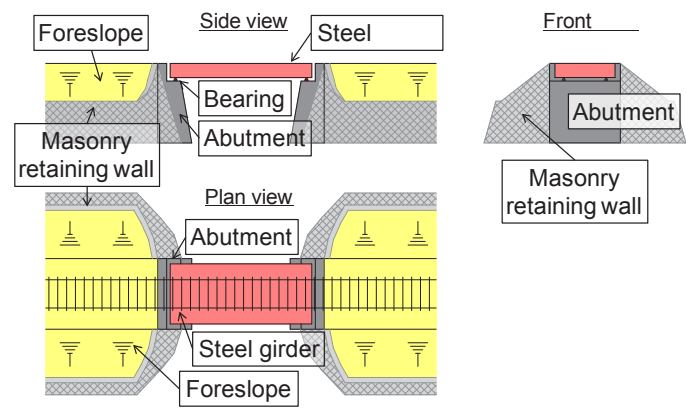

(a) Before reinforcement

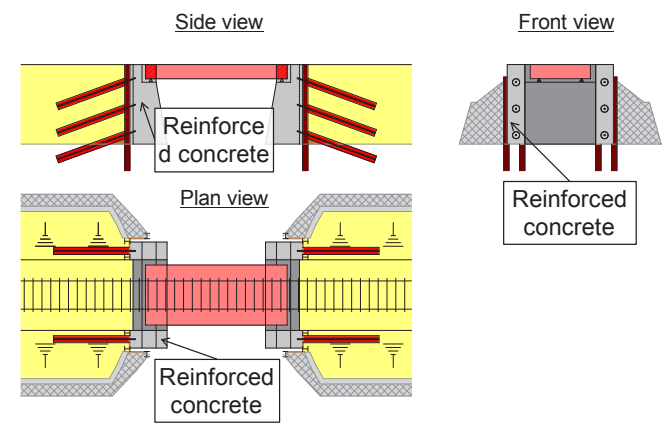

(c) Connecting steel girders and abutments
(1)Abutments and backfills with reinforced concrete (RC) walls that are connected to each other rigidly with nail-reinforced soils;

(2)Connecting steel girders and abutments with reinforced concrete.

These measures reinforce the role played by steel girders, abutments and backfills under normal operational conditions and during earthquakes. The bridges with such a structure are called "Integral Bridge with Nail-Reinforced Soils (NRS-Integral Bridge) [3].” Figure 1 shows the general outline of the proposed method.

Figure 2 shows the work required for integrating deteriorated steel bridges.

(1)Installation of nail-reinforced soil from the side of abutment into the backfill; connection of the abutment and the nail-reinforced soil with reinforced concrete $(\mathrm{RC})$, in order to join the abutment to the backfill;

(2)Lining of the area between the steel girder and the abutment with reinforced concrete to complete the 'integrated' bridge.

The proposed reinforcement method is application of new bridge technology. Since the bearings on abutments absorb the relative displacement between the girder and the abutment, conventional steel-girder and abutment-type bridges do not have sufficient stability under both normal and abnormal conditions. Bridges also have maintenance problems, such as settlement of backfills and corrosion of the steel girders near the bearings.

Geosynthetic-reinforced soil technology is therefore applied to bridges for which reinforced soil abutments made with cement-mixed gravel were developed as shown in Fig.3, in order to solve the problem of backfill settlement and low earthquake resistance. Integral bridges which do not have bearings are the standard type of bridge found

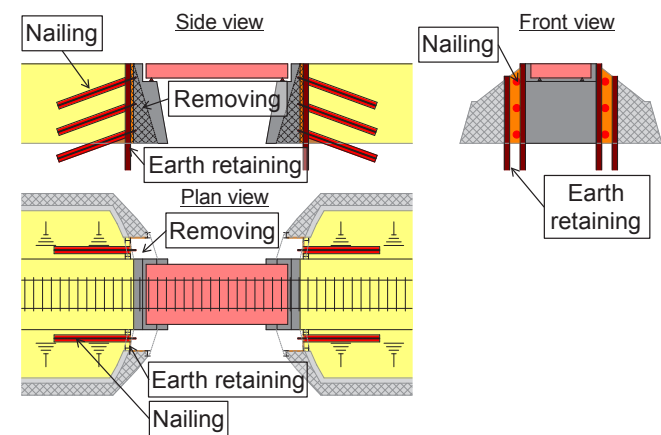

(b) Installation of nails

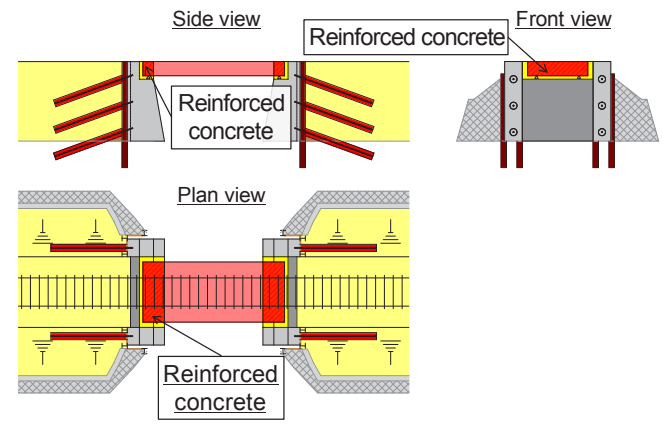

(d) After reinforcement

Fig. 2 Construction process of NRS-Integral Bridge 


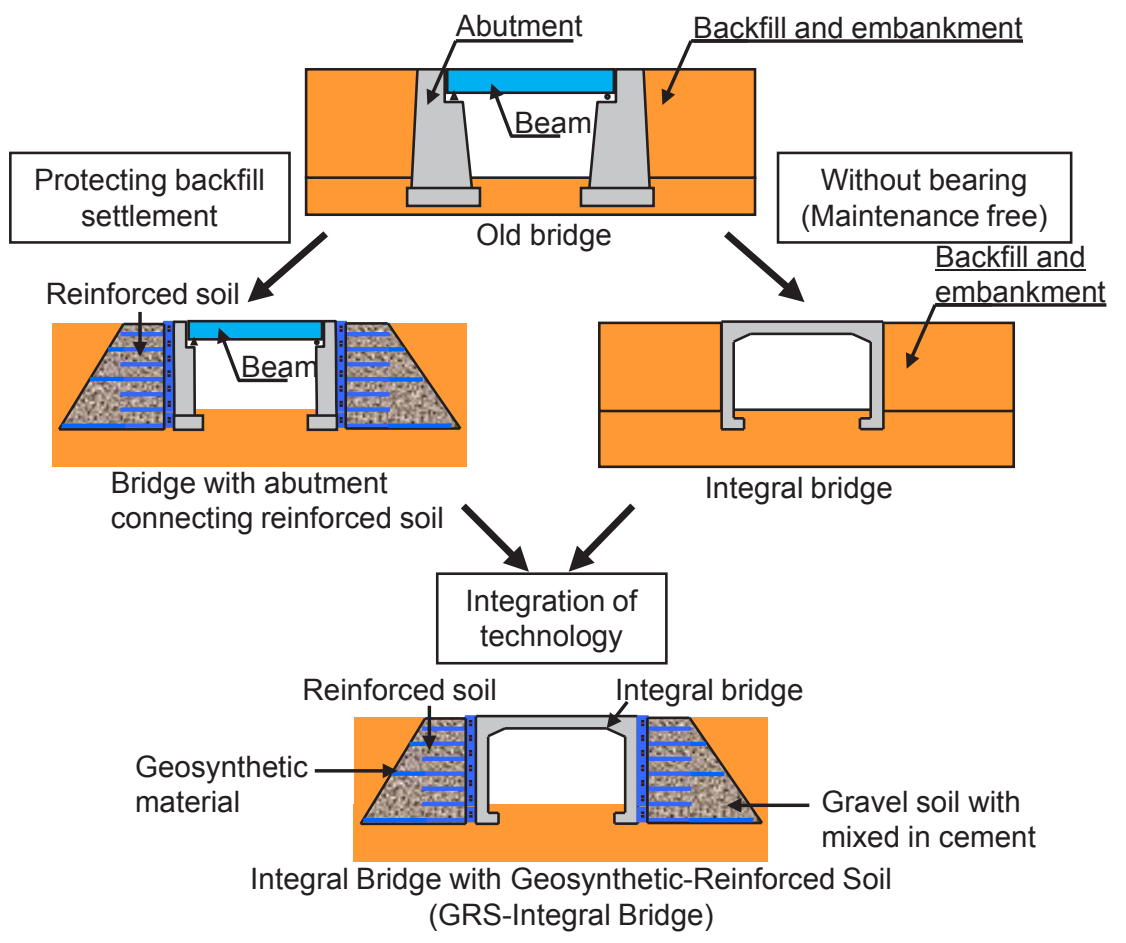

Fig. 3 Integral Bridge with Geosynthetic-Reinforced Soil (GRS-Integral Bridge)

in Europe and America as shown in Fig.3. Bridges with reinforced soil abutments have bearings which still have maintenance problems to be solved. Integral bridges are also subject to other problems such as cracking of abutment surfaces and backfill settlement caused by concrete beams expanding and contracting with changes in temperature. As a result a proposal was made combining both the reinforced soil structure technology and the integral bridge technology, called "Integral Bridge with GeosyntheticReinforced Soil(GRS-Integral Bridge).” In this method, the beams, abutments and backfills are interconnected, in order to improve the various functions of the bridge and backfills, under all circumstances, including emergency conditions [4]. The proposal greatly alters the bridge's structure, i.e. to a thin rigid-frame structure which uses no bearings and no pile foundations because the bridge is supported by reinforced soil backfills made with cement-mixed gravel. This bridge structure has been already been applied to a real bridge in the Hokkaido Shinkansen Project carried out by the Japan Railway Construction, Transport and Technology Agency [5].

"The Integral Bridge with Nail-Reinforced Soil" design is based on the application of the technology used for "Integral Bridge with Geosynthetic-Reinforced Soil." The advantage of such bridges is not only that bearings are no longer required, but also the service life of the steel girders is extended because, by uniting the steel girders with the abutments by virtue of reinforced concrete and burying the bearings in the reinforced concrete, the sectional force at the center of the steel girders when subject to loads from passing traffic is reduced.

Furthermore, bridges constructed in this manner have higher earthquake resistance due to greater soil resistance and possibility of collapse is extremely low since steel girders and abutments form an integrated whole. The stability to train operations afforded by such bridges before, during and after earthquakes is also expected to be greater. Nonetheless, some concerns subsist. Backfills settle because of girders expanding and contracting with changes in temperature, and the surfaces of abutments crack because of increases in pressure from the earth in backfills. However, given that with the proposed structure, abutments and backfills are joined by nail-reinforced soil, there should be less backfill settlement and lower earth pressure, by virtue of the improved stability of the backfill. The latter should also contribute to a decrease in displacement at the top of the abutment due to temperature changes. Table 1 shows the characteristics of the Integral Bridge with NailReinforced Soil.

The authors constructed a full-scale test bridge consisting of steel girders, abutments and backfills in the fieldtrial area at the Railway Technical Research Institute.

Using the experimental bridge, reinforcements were tested. Abutments and backfills built with reinforced concrete (RC) walls were rigidly connected with nail-reinforced soil, and the steel girders and abutments joined through reinforced concrete. A full-scale test bridge is shown in Fig.4. A series of tests were collected for long-term measurements, vertical and lateral repeated loading tests which were conducted before and after the reinforcements, reproducing the equivalent load of a train, girder expansion and contraction and under L2 level earthquake conditions. 


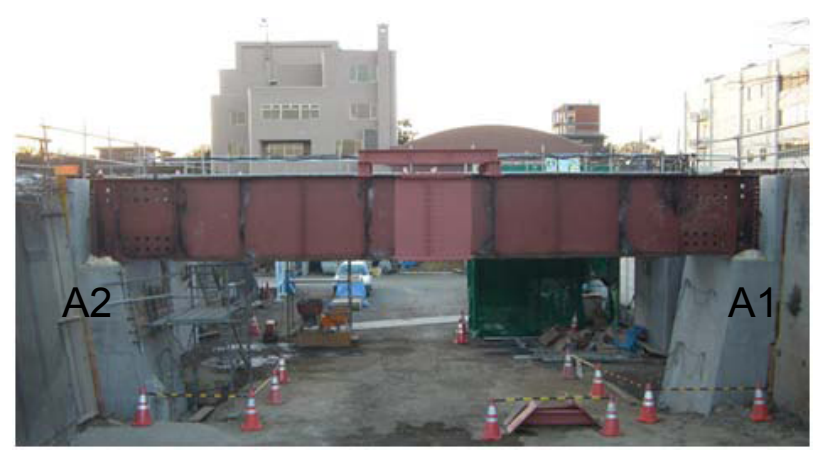

(a) A steel-girder and abutment-type bridge (Before reinforcement)

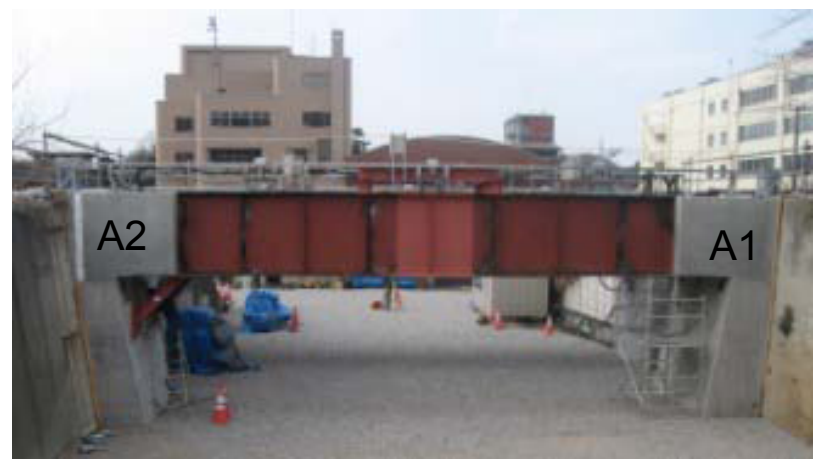

(b) A Integral Bridge with Nail-Reinforced Soil (After reinforcement)

Fig. 4 Appearance of a full-scale test bridge

\section{Verification tests using a full scale test bridge}

4.1 Long-term measurements, motion exciter tests and static loading tests

Measurements were required to confirm the effects of changing temperatures on the steel girders after they had

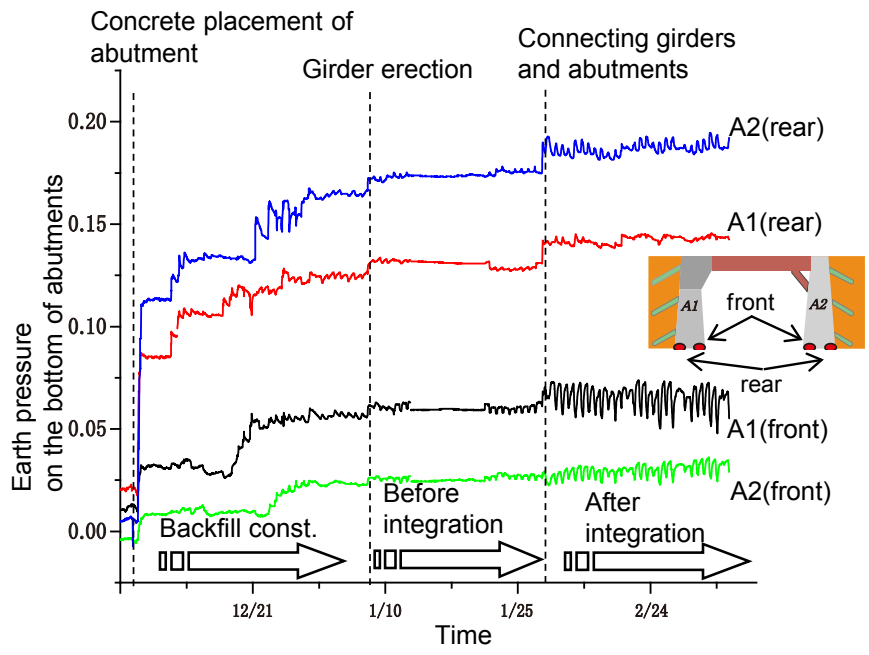

Fig. 5 Earth pressure at the bottom of abutments before and after the integration

been joined to the abutments and backfills with reinforced concrete (RC) and the nail-reinforced soil. To this end, a variety of tests were conducted using a full scale test bridge, including vertical static loading tests and motion exciter tests. These results were used to confirm the effect of integration before and after reinforcement.

Figure 5 shows the earth pressure at the bottom of the abutments before and after integration. The range in change of pressure after integration increases. However, the relative displacement between the abutment and the backfill was very small i.e. about $1.5 \mathrm{~mm}$ per year as shown in Fig.6. The data in the figures were collected at midnight.

Figure 7 shows the strains on the flange of the steel girder before and after integration under the weight of the motion exciter itself $(53 \mathrm{kN})$. The strain after integration decreased by half. Similar results were obtained with the motion exciter tests.
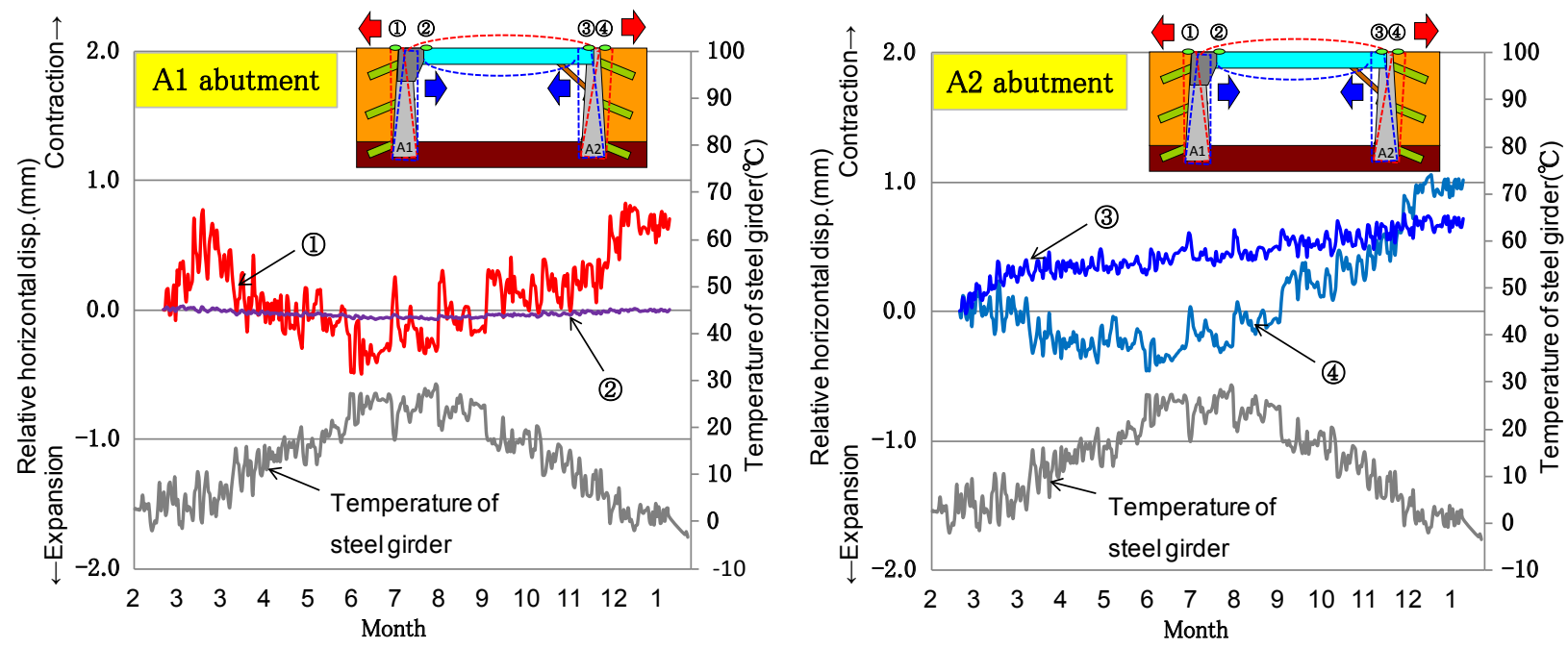

Fig. 6 Relative horizontal disp. between top of abutment and backfill( (1), (4) ), between top of abutment and steel girder( (2), (3) ), temperature of steel girder after the integration 


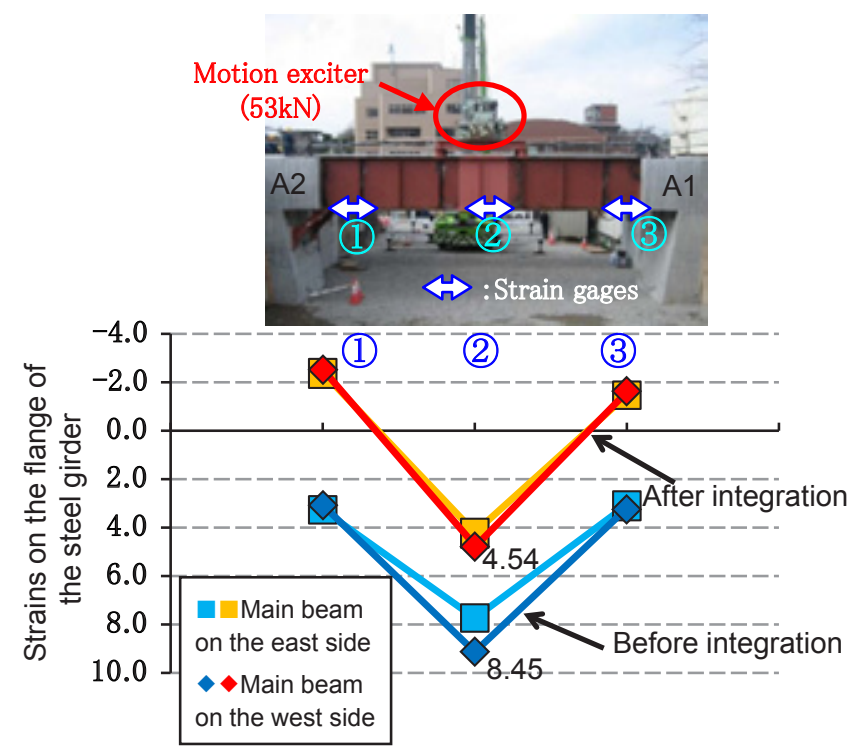

Fig. 7 Strain distributions on the flange of the steel girder before and after the integration

\subsection{Repeated lateral loading tests replicating L2 level earthquake conditions}

Repeated lateral loading tests on the test bridge were carried out in order to confirm its performance under seismic influence and to determine its failure morphol-

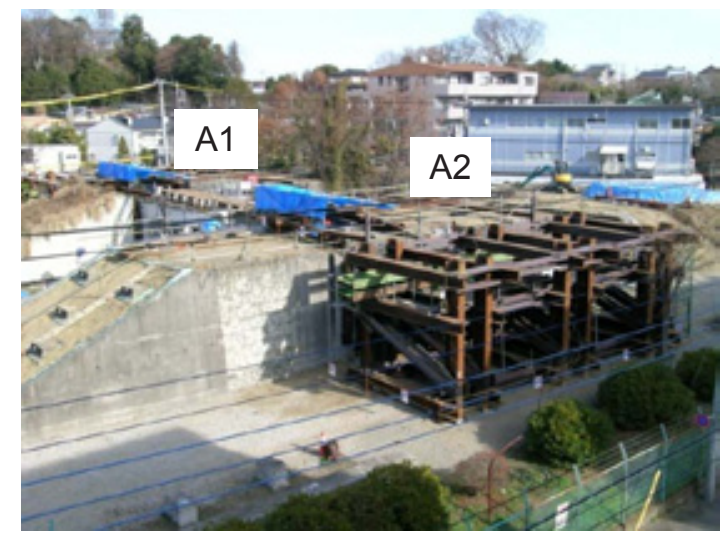

Fig. 8 Appearance of lateral loading tests for a full-scale test bridge

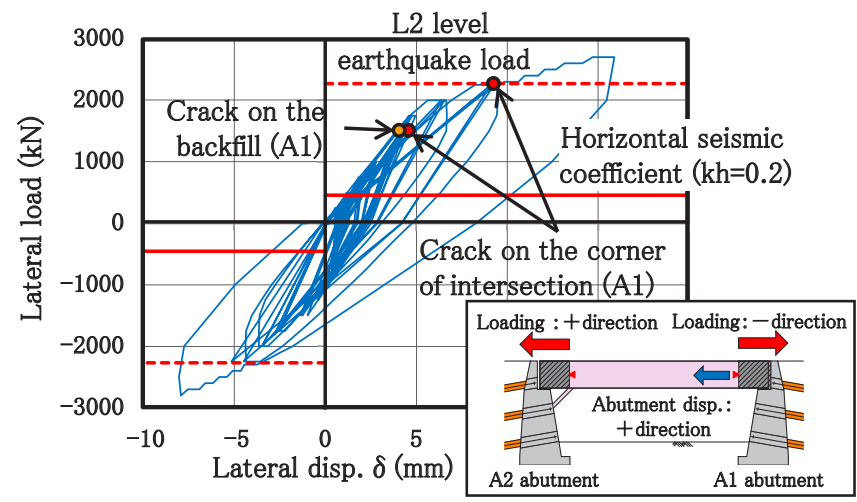

(a) A1 abutment

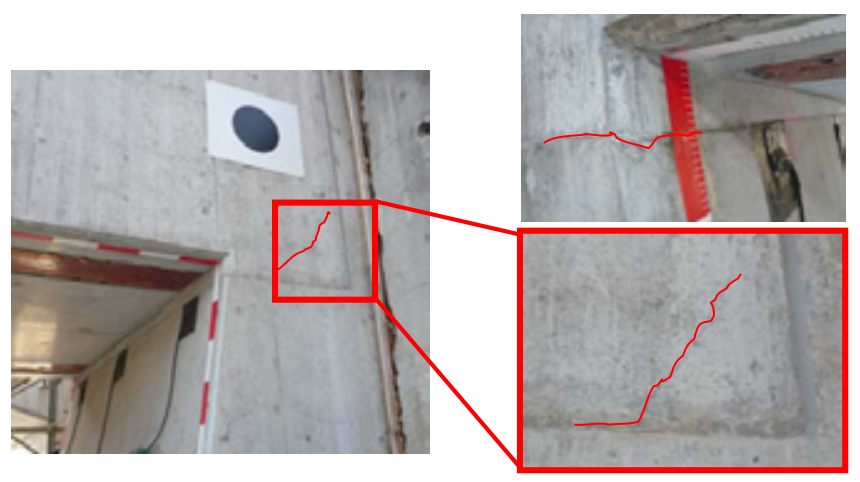

Fig. 10 Appearance of crack on the corner of intersection (A1 abutment)

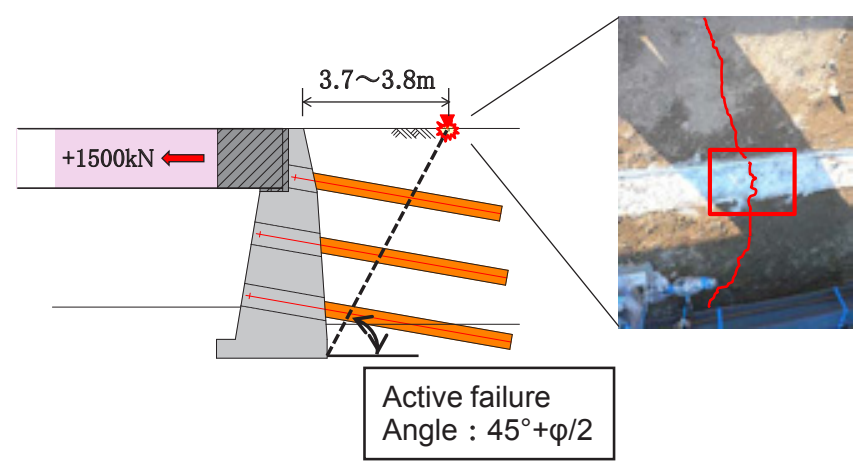

Fig. 11 Appearance of crack on the backfill (A1 abutment)

ogy. Figure 8 shows the test situation and Fig.9 shows the relationship between the lateral load and the displacement at the top of the abutment. The figure shows that lateral displacement at the top of the abutment is $10 \mathrm{~mm}$ under the load of a L2 level earthquake, and is within $5 \mathrm{~mm}$ after unloading. Figure 10 and Fig. 11 show the damage to the corner of the bridge intersection and the backfill. Both the corners and the backfills are slightly damaged.

\section{Conclusions}

In order to extend the life and strengthen the earthquake resistance of deteriorated steel-girder and abutment-type bridges without replacing steel girders, it is necessary to improve the stability of the interface between

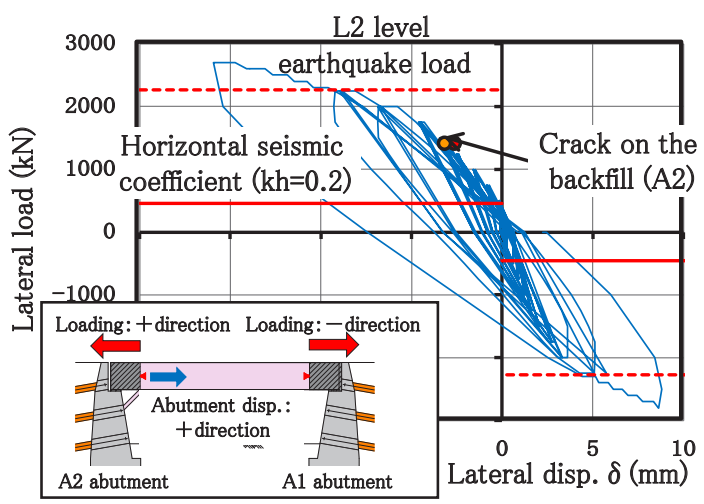

(b) A2 abutment

Fig. 9 Relationships between lateral load and disp. at the top of abutments 
the backfill and the abutment, and to increase the strength of the deteriorated steel bridges. On the basis of what is described in previous sections of this paper, the Railway Technical Research Institute proposed a method to reinforce deteriorated steel bridges with nail-reinforced soil.

It is clear that Integral Bridges with Nail-Reinforced Soil are highly stable not only under normal circumstances but also in emergency conditions such as during an earthquake. The proposed method is an excellent means of reinforcement because there is no need to replace the steel girders.

The proposed method intended to reinforce deteriorated steel-girder and abutment-type bridges should make a significant contribution to extending the service life and strengthening the earthquake resistance of bridges. This method therefore together with the method for improving backfills and embankments with nail-reinforced soil should be a significant contribution to improving the sustainability of several railway lines.

\section{Acknowledgement}

This study was received with financial support from the Ministry of Land, Infrastructure, Transport and Tourism.

\section{References}

[1] Tateyama, M., "Seismic Diagnosis and Reinforcement for Railway Soil Structures," Geotechnical Engineering Magazine, Vol.59, No.7, Ser.No.642, pp82-89, 2011 (in Japanese).

[2] Railway Technical Research Institute, "Railway Damage Research Reports in Hyogoken Nambu Earthquake, "RTRI Report, Special Issue No.4, pp.89-90, 1996 (in Japanese).

[3] Koda, M., Suga, T., Nonaka, T., Yokoyama, T. and Tateyama, M., "Integrated Reinforcement Technology for Boundary Area between Backfill and Abutment in Railway," Proceedings for Geotechnical Engineering Symposium, pp.9-16, 2011 (in Japanese).

[4] Tatsuoka, F., Hirakawa, D., Nojiri, M., Aizawa, H., Nishikiori, H., Soma, R., Tateyama,M. and Watanabe,K. "A New Type Integral Bridge Comprising Geosynthetic-Reinforced Soil Walls," Proceedings of Gesynthtetics International, Vol.16, No.4, pp.301-326, 2009.

[5] Watanabe, K., "Application of Integrated Bridges with Geosynthetic-Reinforced Soil (GRS-Integral Bridges) to the Hokkaido Shinkansen," Japanese Railway Facilities Magazine, Vol.49, No.10, pp.880-883, 2011 (in Japanese). 